\title{
Audit on Preparations for Pediatric Cardiac Catheterization
}

\author{
SHYMAA A. MOHAMMED, M.Sc.; AHMED R. AHMED, M.D. and DUAA M. RAFAAT, M.D. \\ The Department of Pediatrics, Faculty of Medicine, Assiut University Assiut, Egypt
}

\begin{abstract}
Background: Interventional cardiac catheterization describes procedures where cardiac catheters are used to modify, palliate, or treat congenital or acquired cardiac diseases. Adequate preparation of the patient before the procedure and careful monitoring during the procedure can minimize complications and fatality from invasive studies.

Aim of Study: To assess degree of adherence of medical physicians to Assiut university children hospital protocols for preparations of pediatric cardiac catheterization according to Society for Cardiovascular Angiography and Intervention (SCAI) guidelines.

Patients and Methods: The study aims to assess the preparations for pediatric cardiac catheterization among children admitted to Catheterization Laboratory of Assuit University Children 's Hospital from 1 st of January 2016 to 31 th of July 2016 using a standard report, also we assessed the preparations retrospectively from 1 st of January 2015 to $31^{\text {th }}$ December 2015.

Results: The study included 230 patients with congenital heart disease. Their age ranged from 6 months to 18 years, 90 cases were males and 140 were females. Data of the study showed that the preparations for pediatric cardiac catheterization in Assiut University Children's Hospital partially followed the reference standard of the study.

Conclusion: In brief, preparations for cardiac catheterization is done to maximize the patient's safety, that represent the doctor's main target. So, Adequate preparations of the patient before the procedure and careful monitoring during the procedure can minimize complications and fatality from invasive studies, and achieve a pleasing procedure outcome of the department of pediatric cardiology diagnostic and interventional procedures.
\end{abstract}

Key Words: Cardiac catheterization - Congenital heart disease - Preparations.

\section{Introduction}

INTERVENTIONAL cardiac catheterization describes procedures where cardiac catheters are used to modify, palliate, or treat congenital or acquired cardiac diseases. Cardiac catheterization has long

Correspondence to: Dr. Shymaa A. Mohammed, Email: Mohamed.abdalkarem132@gmail.com served as the "gold standard" for the anatomic and physiological assessment of patients with CHD $[1,2]$

The Society of Invasive Cardiovascular Professionals (SICP) has published, with the endorsement of the Society for Cardiovascular Angiography and Interventional (SCAI), the 2015 Educational Guidelines for Invasive Cardiovascular Technology Personnel in the Cardiovascular Catheterization Laboratory. The aims of these guidelines are to improve patient outcome and to provide acceptable standards of practice for the therapeutic cardiac catheterization procedures. Adequate preparations of the patient before the procedure and careful monitoring during the procedure can minimize complications and fatality from invasive studies. These preparations should include adequate history taking, complete examination, and all the investigations needed [3]

\section{Pre-operative preparation:}

- Routine nursing admission procedures should be followed.

- Accurate weight and height measurement will aid the cardiologist to choose the appropriate catheter size.

- Checking vital signs: Temperature, pulse, respirations, blood pressure and oxygen saturations. Pulse rate should be checked for one minute for signs of any arrhythmias [4]

- Assessment and document of baseline neurovascular observations. Check all four limbs and assess all pulses including the dorsalis pedis, posterior tibial and radial.

- Obtain an up-to-date history of the child's current medication regime from the parents/career. Some medications will need to be ceased pre-operatively after discussion with the Cardiologist.

- Ensure consent form is signed and completed. 
- Fasting times are to be ordered by an Anaesthetist for all procedures. An anaesthetist can also order pre medications if needed.

- Some children may require intravenous (IV) fluids to prevent dehydration. The Cardiology team and anaesthetist will identify any patients who require IV access.

- Give the patient a bath on the morning of the procedure using a chlorhexadine gluconate $2 \%$ body wash [5]

- Inform parents/careers of all pre-operative and post-operative care needs.

- All high risk cardiac catheterizations must have a post-operative bed booked via the Theatre Scheduler in PICU [6].

\section{Patients and Methods}

Study site: Assiut university children hospital, Catheterization Laboratory.

\section{Inclusion criteria:}

Include all the admitted cases with cardiac diseases to The Pediatric Cardiac Unit for catheterization (whether diagnostic or therapeutic) from January 2016 to July 2016 prospectively, also the admitted cases retrospectively from January 2015 to December 2015.

\section{Exclusion criteria:}

- All patients above age of 18 years.

- Critically ill infants and children.

- The emergency catheterization and the electrophysiology.

\section{Results}

The study included 230 patients with congenital heart disease.

Table (1): Showed that age ranged from 6 months to 18 years with a mean of 4.48 , data of present study showed that 90 cases were male and 140 cases were female, and that weight ranged from $6 \mathrm{~kg}$ to $63 \mathrm{~kg}$.

Table (2): Showed that assessment of general appearance, growth pattern and respiratory system was recorded only in 8 cases. Determination of heart rate and regularity was recorded in 213 cases (92.6\%). Cardiac examination was assessed in 209 cases $(90.9 \%)$, assessment of gastrointestinal system was recorded in 7 cases.
Table (3): showed that complete blood count, assessment of blood urea and creatinine, and measurement of coagulation profile (PT, PC, INR, aPTT) were properly done in $99.6 \%$ of cases. Measurement of blood glucose was done in 34 cases only. measurement of electrolytes was done in $98.7 \%$ of cases.

Table (4): Showed that the consent form was recorded in $92.2 \%$ of cases, $99.6 \%$ of cases had intravenous line and received pre-operative sedation. Pre-operative fasting was done in $100 \%$ of cases, but duration of fasting was done in improper way. Nursing care was done in 176 cases $(76.5 \%)$.

Table (5): Showed that the catheterization procedure was done in 185 cases $(80.4 \%)$.

Table (6): Showed various types of procedures were done in studied cases. Transcatheter septal closure was being the most frequent procedure done in 82 cases $(44.3 \%)$, pulmonary balloon valvoplasty was done in 24 cases hemodynamic study was done in 11 cases, diagnostic catheterization was done in 13 cases. Amplarzer ductal closure was done in 48 cases. Aortic balloon valvoplasty was done in 6 cases, and balloon angioplasty was done in one case.

Table (7): Showed recorded data about different causes in studied cases were the catheterization was not done. Anemia was recorded in 8 cases, 5 cases were diagnosed as gastroenteritis, 22 cases had chest infection. Skin abscess, vomiting, and impaired coagulation profile were diagnosed in $4.4 \%$ of cases separately. 4 cases had tonsillitis.

Table (1): Recorded data of age and sex of the studied cases.

\begin{tabular}{|c|c|c|}
\hline & No. $(n=230)$ & $\%$ \\
\hline \multicolumn{3}{|l|}{ Age: } \\
\hline$<2$ years & 61 & 26.5 \\
\hline $2-<4$ years & 69 & 30.0 \\
\hline $4-<6$ years & 35 & 15.2 \\
\hline$>6$ years & 65 & 28.3 \\
\hline Mean \pm SD & \multicolumn{2}{|c|}{$4.48 \pm 4.29$} \\
\hline Median (Range) & \multicolumn{2}{|c|}{$3.0(0.5-18.0)$} \\
\hline \multicolumn{3}{|l|}{ Sex: } \\
\hline Male & 90 & 39.1 \\
\hline Female & 140 & 60.9 \\
\hline \multicolumn{3}{|l|}{ Weight $(\mathrm{kg})$ : } \\
\hline Mean \pm SD & \multicolumn{2}{|c|}{$16.73 \pm 10.49$} \\
\hline Median (Range) & \multicolumn{2}{|c|}{$13.0(6.0-63.0)$} \\
\hline
\end{tabular}


Table (2): Recorded data about clinical examination.

\begin{tabular}{lllll}
\hline & \multicolumn{2}{c}{ Done } & \multicolumn{2}{c}{ Not done } \\
\cline { 2 - 5 } & No. & $\%$ & No. & $\%$ \\
\hline $\begin{array}{c}\text { General appearance } \\
\text { and growth pattern }\end{array}$ & 8 & 3.5 & 222 & 96.5 \\
$\begin{array}{c}\text { Respiratory tachypnea, } \\
\text { retractions, and } \\
\text { hypoxemia }\end{array}$ & 8 & 3.5 & 222 & 96.5 \\
$\begin{array}{c}\text { Heart rate and } \\
\text { regularity }\end{array}$ & 213 & 92.6 & 17 & 7.4 \\
$\begin{array}{c}\text { Heart sounds } \\
\text { (intensity, quality) }\end{array}$ & 209 & 90.9 & 21 & 9.1 \\
$\begin{array}{c}\text { Heart murmurs } \\
\text { (intensity, location, } \\
\text { transmission) }\end{array}$ & 209 & 90.9 & 21 & 9.1 \\
$\begin{array}{c}\text { Gastrointestinal } \\
\text { system }\end{array}$ & 7 & 3.0 & 223 & 97.0 \\
\hline
\end{tabular}

Table (3): Recorded data about laboratory investigations in 230 studied cases.

\begin{tabular}{lllll}
\hline & \multicolumn{2}{c}{ Recorded } & \multicolumn{2}{c}{ Not recorded } \\
\cline { 2 - 5 } & No. & $\%$ & No. & $\%$ \\
\hline Complete blood count & 229 & 99.6 & 1 & 0.4 \\
Blood glucose & 34 & 14.8 & 196 & 85.2 \\
Electrolytes & 227 & 98.7 & 3 & 1.3 \\
Arterial blood gases & 26 & 11.3 & 204 & 88.7 \\
Blood urea nitrogen, & 229 & 99.6 & 1 & 0.4 \\
$\quad$ creatinine & & & & \\
Coagulation profile: & & & & \\
$\quad$ INR, PT, PTT & 229 & 99.6 & 1 & 0.4 \\
Chest X-rays & 230 & 100.0 & 0 & 0.0 \\
Baselines ECG & 230 & 100.0 & 0 & 0.0 \\
ECHO & 230 & 100.0 & 0 & 0.0 \\
\hline
\end{tabular}

Table (4): Recorded data about consent and pre-operative preparation.

\begin{tabular}{lcccc}
\hline & \multicolumn{2}{c}{ Done } & \multicolumn{2}{c}{ Not done } \\
\cline { 2 - 5 } & No. & $\%$ & No. & $\%$ \\
\hline $\begin{array}{c}\text { Whether the consent } \\
\text { form is signed or not }\end{array}$ & 212 & 92.2 & 18 & 7.8 \\
$\begin{array}{c}\text { Intravenous (I.V) line } \\
\text { is secure and patent }\end{array}$ & 229 & 99.6 & 1 & 0.4 \\
$\begin{array}{c}\text { Pre-operative fasting } \\
\text { Pre-operative sedation }\end{array}$ & 230 & 100.0 & 0 & 0.0 \\
Nursing care & 176 & 99.6 & 1 & 0.4 \\
\hline
\end{tabular}

Table (5): Recorded data denoting cases in which catheterization was done.

\begin{tabular}{lcc}
\hline Catheterization & No. $(\mathrm{n}=230)$ & $\%$ \\
\hline Done & 185 & 80.4 \\
Not done & 45 & 19.6 \\
\hline
\end{tabular}

Table (6): Recorded date about type of the procedures done.

\begin{tabular}{lcl}
\hline Type of procedure & No. $(\mathrm{n}=185)$ & $\%$ \\
\hline Transcatheter septal closure & 82 & 44.3 \\
Hemodynamic study to measure & 11 & 5.9 \\
pulmonary vascular resistance & & \\
Diagnostic & 13 & 7.0 \\
Pulmonary balloon valvoplasty & 24 & 13.0 \\
Amplatzer ductal closure & 48 & 25.9 \\
Aortic balloon valvoplasty & 6 & 3.2 \\
Transcatheter balloon angioplasty & 1 & 0.5 \\
\hline
\end{tabular}

Table (7): Recorded data about causes in cases where catheterization was not done.

\begin{tabular}{lcc}
\hline Cause & No. $(\mathrm{n}=45)$ & $\%$ \\
\hline Gastroenteritis & 5 & 11.1 \\
Anemia $(\mathrm{Hb}<8 \mathrm{mg} / \mathrm{dl})$ & 8 & 17.8 \\
Chest infection & 22 & 48.9 \\
Skin abscess & 2 & 4.4 \\
Impaired coagulation profile & 2 & 4.4 \\
Tonsillitis & 4 & 8.9 \\
Fever, vomiting & 2 & 4.4 \\
\hline
\end{tabular}

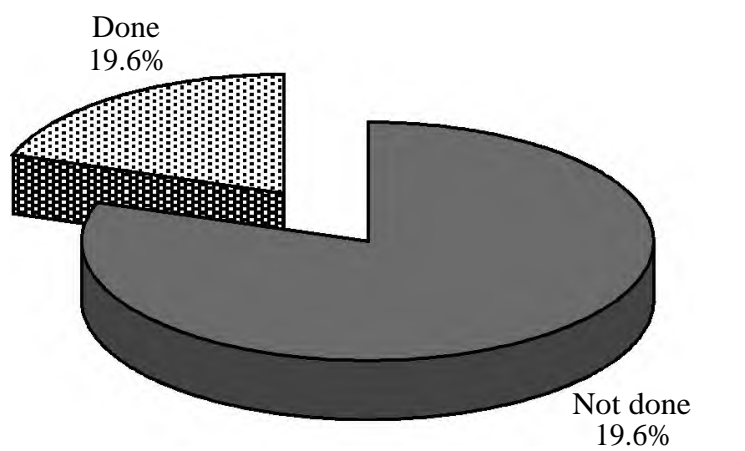

Fig. (1): Percentage of cases where catheterization was done.

\section{Discussion}

To keep safe, Adequate preparation of the patient before the procedure and careful monitoring during the procedure can minimize complications and fatality from invasive studies. These preparation should include adequate history taking, complete examination, and all the investigations needed [7]

To support the ongoing training of cardiovascular technologists and provide an educational framework for invasive cardiovascular training programs, the Society of Invasive Cardiovascular Professionals (SICP) has published, with endorsement of the Society for Cardiovascular Angiography and Interventional (SCAI), the 2015 Educational Guidelines for Invasive Cardiovascular Technology 
Personnel in the Cardiovascular Catheterization Laboratory. The aims of these guidelines are to improve patient outcome and to provide acceptable standards of practice for the therapeutic cardiac catheterization procedures.

In this study 230 cases of children with cardiac disease were admitted at Pediatric Cardiac Unit for catheterization (whether diagnostic or therapeutic) from 1 st of January 2016 to 31 th of July 2016 prospectively, also the admitted cases where studied retrospectively from 1 st of January 2015 to $31^{\text {th }}$ December 2015.

History taking is a basic step in cardiac evaluation. It should include personal history, history of present illness, past history, including the immediate postnatal period, providing more direct information relevant to the cardiac evaluation. Family history also helps to link a cardiac problem to other medical problems that may be prevalent in the family [8]

In the present study regarding data of the history, it was partially following the reference standard of the study. Personal history (name, age, and sex...etc.) was fulfilled in $100 \%$ of cases, history of birth date was recorded in $99.1 \%$ of cases, but history of weight gain was not recorded in $97.8 \%$ of cases, feeding pattern was not recorded in $100 \%$ of cases, family history of hereditary diseases or congenital heart disease were not recorded in $99.6 \%$ of cases. Data about weight were recorded well in $100 \%$ of cases.

As with the examination of any child, the order and extent of the physical examination of infants and children with potential cardiac problems should be individualized. Vital signs: Temperature, pulse, respirations, blood pressure and oxygen saturations should be checked [4]

In the present study regard recording vital signs, assessment of heart rate, respiratory rate were recorded in $97.8 \%$ of cases, and assessment of blood pressure was done in all cases.

As for general appearance and nutritional state; any obvious syndrome or chromosomal abnormalities; color (i.e., cyanosis, pallor); clubbing; respiratory rate, dyspnea, and retraction; and chest inspection should be recorded [9]. The physician should note whether the child is in distress, well nourished or undernourished. ENT examination may reveals ear infection, otitis media, discharge, nasal discharge, sore throat, tonsillitis [10]. Chest examination must be done in all cases, Pattern of breathing, respiratory rate, use of accessory muscles: Retraction, degree/flaring, equality of breath sounds, rales, wheezes, rhonchi should also be detected [9].

In cardiac examination, the heart should be examined in a systematic manner. Several clinical signs may be appreciated upon examination and auscultation of the heart [11]

In our study, Determination of heart rate and regularity were recorded in 213 cases $(92.6 \%)$. Cardiac examination was assessed in 209 cases (90.9\%), assessment of gastrointestinal system was recorded in 7 cases.

Every child undergoing cardiac catheterization should have the baseline investigations, which include 12- lead ECG, chest radiographs (both PA and lateral), two dimensional Echo, urine analysis, complete blood count with differential white blood count within days or weeks in advance of the study, baseline coagulation studies and platelet count for deeply cyanotic child [1] .

All studied cases had baseline investigations including chest X-ray, ECG and transthoracic echocardiography. Measurement of electrolytes, blood urea and creatinine, coagulation profile and complete blood count were fulfilled, but blood glucose and arterial blood gases were not assessed in $85.2 \%$ and $88.7 \%$ of cases, respectively. Data about imaging studies (chest X-rays, Echo), and ECG were fulfilled well in $100 \%$ of cases.

As regard pre-operative preparation, consent form must be signed and completed. Fasting times are to be ordered by an Anaesthetist for all procedures, applying "the 6/4/2" rule. An anaesthetist can also order pre medications if needed. Some children may require intravenous (IV) fluids to prevent dehydration. The Cardiology team and anaesthetist will identify any patients who require IV access. The child is admitted to the children's ward one day before the procedure. Routine nursing admission procedures should be followed [5]

In our study, the consent form was recorded in $92.2 \%$ of cases, $99.6 \%$ of cases had intravenous line and received pre-operative sedation. Preoperative fasting was done in $100 \%$ of cases, but duration of fasting was done in improper way. This point is mandatory and so found deficient, and "the 6/4/2 " rule was not applied. All the cases were fasting for more than eight hours, and were given intravenous fluids. Nursing care was done in 176 cases $(76.5 \%)$. 
In the present study, diagnostic catheterization was done in 24 cases (13\%), while therapeutic catheterization was done in 161 cases $(87 \%)$.

In the present study, the catheterization procedure was done in 185 cases $(80.4 \%)$, while it was cancelled in 45 cases $(19.6 \%)$.

In our study, there are various types of procedures done in studied cases, Transcatheter septal closure was the most frequent procedure done in 82 cases $(44.3 \%)$, pulmonary balloon valvoplasty was done in 24 cases, hemodynamic study was done in 11 cases, diagnostic catheterization was done in 13 cases. Amplatzer ductal closure was done in 48 cases. Aortic balloon valvoplasty was done in 6 cases, and balloon angioplasty was done in one case.

Recorded data about the cases in which the catheterization was not done showed that the catheterization was not done in 45 cases due to different causes in studied cases. Anemia was recorded in 8 cases, 5 cases were diagnosed as gastroenteritis, 22 cases had chest infection. skin abscess, vomiting, and impaired coagulation profile were diagnosed in $4.4 \%$ of cases separately. 4 cases had tonsillitis, and all these causes not observed by resident doctors.

\section{Conclusion:}

In brief, preparations for cardiac catheterization are done to maximize the patient's safety, that represent the doctor's main target. So, Adequate preparations of the patient before the procedure and careful monitoring during the procedure can minimize complications and fatality from invasive studies, and achieve a pleasing procedure outcome from the department of pediatric cardiology diagnostic and interventional procedures.

\section{References}

1- MULLINS C.E. and NIHIL M.R.: Cardiac Catheterization hemodynamics and Intervention. In: Moller J.H. , Hoffman H.E., ed. Pediatric Cardiovascular Medicine, New York: Churchill Livingstone: 203-215, 2005.

2- LEGENDRE A. and BOUDJEMLINE Y.: Percutaneous treatment of congenital heart valve diseases. Arch Cardiovasc Dis., 3: 173-182, 2011.

3- BONNET C. and GREFFIER A.: Paediatric cardiac catheterization: An information sheet. Arch. Cardiovasc. Dis., 106: 228-237, 2013.

4- SARTI A., SAVRON F., RONFANI L., PELIZZO G. and BARBI E.: Comparison of three sites to check the pulse and count heart rate in hypotensive infants. Paediatri Anaesth., 16: 394-398, 2006.

5- HOCKENBERRY M.J. and WILSON D.: Wong's essentials of pediatric nursing , 9 th ed. Missouri: Mosby, 2013

6- CHAIR S.Y., THOMPSON D.R. and LI S.K.: The effect of ambulation after cardiac catheterisation on patient outcomes. Journal of Clinical Nursing. Jan., 16 (1): 212 214, 2007.

7- KERN M.J., SORAJJA P., LIM M.J., et al.: The Cardiac Catheterization Handbook, 6 th ed. Philadelphia., 978-0 323-34039-7, 2016.

8- FELTES T.F., BACHA E., BEEKMAN III R.H., CHEATHAM J.P., FEINSTEIN J.A., GOMES A.S., HIJAZI Z.M., de, MORROW W.R., MULLINS C.E. and ZAHN E.M.: Indications for cardiac catheterization and intervention in pediatric cardiac disease: A scientific statement from the American Heart Association. Circulation. May., 123: 2607-2652, 2011.

9- HUGE D. ALLEN, ROBERT E. SHADDY, DANIEL J. PENNY, TIMOTHY F. FELTES and FRANK CETTA: Moss and Adams' Heart Disease in Infants, Children, and Adolescents. March, 9781451118933, 2012.

10- KEANE J.F., LOCK J.E. and FYLER D.: Aortic outflow abnormalities. In: Nadas, Pediatric Cardiology, Keane J.F., Lock J.E., Fyler D., et al. Saunders / El Servier, Philadelphia. p. 581, 2006.

11- BRAUNWALD E. and PERLOFF J.K.: Physical examination of the heart and circulation. In: Braunwald E., Zipes D.P., Libby P., ed. Heart Disease, 10 th ed. Philadelphia: WB Saunders: 5-81, 2014. 


\section{دراسة تلدقيقية على الأعمال التحضيرية لقسطرة القلب للأطفال}

تعتبر القسطرة القلبية وتخطيط القلب والأوعية الدموية من الفحصات التشخيصية النهائية لمعظم مرضى القلب.

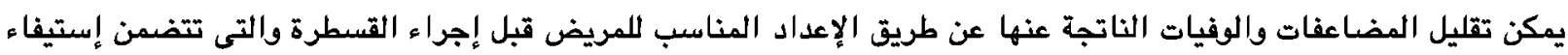

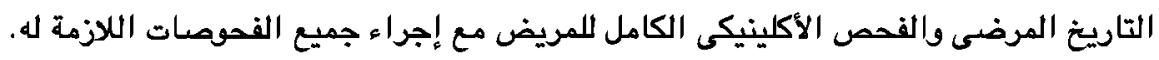

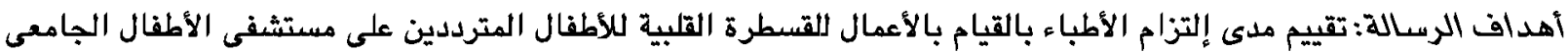

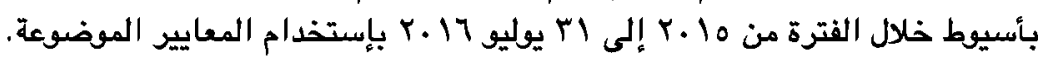

الأطفال المستهدفين: كل الأطفال الذين يعانون من أمراض قلبية والمترددين على وحدة القلب بمستشفى الأطفال الجامعى بأسيوط

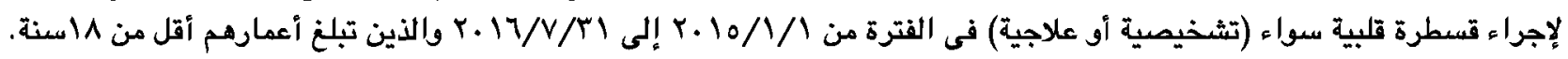

الأطفال المستبعدين:

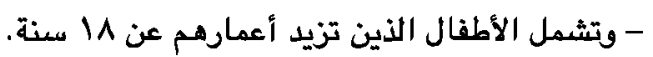

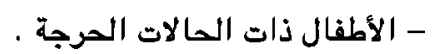

- حالات القسطرة الطارئة.

النتائج: تتضمن الرسالة . بr حالة يعانون من أمراض القلب الخلقية ، يتراقع عمرهم من جثهود - ^| سنة، عدد الذكود .9 وعدد

الإناث • عالة حالة.

وأظهرت بيانات الدراسة أن الأعمال التحضيرية للقسطرة القلبية للأطفال أتبعت جزئياً المعايير المرجعية للدراسة. التوصيات: لتحقيق نتائج أفضل، وتوفير الوقت والجهد وتقليل الخاطر المحتملة من الأعمال التحضيرية الغير ملائمة المريض قبل القسطرة يجب: التوه:

ا - التأكيد على إستيفاء البيانات الخاصة بالتاريخ المرضى من الابوين أو الأقارب وتسجيلها بالكامل بملف المريض. ب- الفحص الأكلينيكى الشامل للمريض مع تسجيل ايى مثكلة صحية تتعلق بالمريض. r- إتباع المعايير المرجعية للأعمال التحضيرية للقسطرة القلبية.

ع- تحسين الإمكانيات مثل استخدام أجهزة رسم القلب الجيدة أجهزة قياس النبض وإتاحة فحصصات معملية ثاملة. ه- يجب على طبيب التخدير أن يقوم بتنظيم وقت الصيام المناسب للمريض قبل إجراء القسطرة القلبية طبقاً لعمر المريض. 